\title{
FÁBRICAS RECUPERADAS PELOS TRABALHADORES: os dilemas da gestão coletiva do trabalho' ${ }^{1}$
}

\author{
Aline Suelen Pires* \\ Jacob Carlos Lima* *
}

\begin{abstract}
Este artigo objetiva analisar os dilemas da gestão coletiva em fábricas recuperadas pelos trabalhadores no Brasil, organizadas, em sua maioria, na década de 1990. Essas fábricas foram estruturadas ora como cooperativas, ora como formas híbridas de gestão, num contexto de reestruturação econômica e aumento do desemprego, para manter postos de trabalho. Em geral, elas tiveram apoio de sindicatos, e progressivamente se inseriram no movimento de Economia Solidária que se institucionalizou na década seguinte. Após 20 anos do surgimento dos primeiros empreendimentos desse tipo, buscamos não só verificar como eles se mantiveram no mercado e se adaptaram às mudanças político-econômicas do período, mas também analisar sua relação com as propostas originais de autogestão. A pesquisa teve um recorte longitudinal, buscando estudar fábricas analisadas anteriormente (no final dos anos 1990) e que permaneciam em atividade. Também foram realizadas entrevistas com lideranças e trabalhadores dos empreendimentos, bem como com lideranças de instituições de apoio como a ANTEAG e a UNISOL Brasil. Embora os ideais do cooperativismo e da chamada autogestão permaneçam presentes nos discursos de muitos trabalhadores, sua efetivação encontra muitos obstáculos na prática, uma vez que, para serem viáveis, as fábricas recuperadas enfrentam muitas pressões do mercado, que acabam por modificar alguns de seus objetivos iniciais.

Palavras-chave: Trabalho. Autogestão. Cooperativismo. Economia solidária. Fábricas recuperadas.
\end{abstract}

\section{INTRODUÇÃO}

Desde o século XIX, quando surge, o movimento cooperativista foi considerado polêmico no movimento operário. De um lado, estavam aqueles que o consideravam como o ponto de partida para um novo modo de produção; de outro, aqueles que o tinham como meramente reformista. De Marx (1977) a Luxemburgo (1979), foram apontadas as vantagens e desvantagens das cooperativas, sendo que os riscos mais comumente apontados eram a possibilidade de os trabalhadores virarem patrões de si mesmos e se autoexplorarem, e o fato de que o sucesso das cooperativas, no mercado

\footnotetext{
* Universidade Federal de São Carlos (UFSCar). Centro de Educação e Ciências Humanas. Departamento de Sociologia. Rodovia Washington Luís Km 235. Monjolinho. Cep: 13565-905. São Carlos - São Paulo - Brasil. aline.sociologia@gmail.com

** Universidade Federal de São Carlos (UFSCar). Centro de Educação e Ciências Humanas. Departamento de Sociologia. Rodovia Washington Luís Km 235. Monjolinho. Cep: 13565-905. São Carlos - São Paulo - Brasil. jacobl@uol.com.br

${ }^{1}$ Este artigo discute resultados da tese de doutorado intitulada "Fábricas recuperadas e os trabalhadores: a autogestão entre a teoria e a prática”, de autoria de Aline Suelen Pires e orientada por Jacob Carlos Lima. Essa pesquisa teve apoio da Fundação de Amparo à Pesquisa do Estado de São Paulo (FAPESP).
}

capitalista, as tornaria empresas como quaisquer outras (Webb; Webb, 1914). Esse debate marcou o final do século XIX e início do século XX. Posteriormente a esse período, foram implantadas cooperativas nos países socialistas (como política de Estado) e, nos países ocidentais, seu crescimento ficou vinculado a períodos de crise econômica (Lima, 2002). Com a implementação do Estado de bem-estar social, a vinculação do trabalho e dos direitos sociais (Harvey, 1993), assim como a construção do que Castel (1998) chamou de "sociedade salarial”, as cooperativas, em países como França, Itália e Espanha, embora significativas, tiveram um papel secundário e integrado à economia de mercado, constituindo-se, na França, em mais um setor chamado de "economia social” (Laville, 2001).

No Brasil, diversas situações passaram a caracterizar as cooperativas e fábricas recuperadas, num continuum dependente do êxito desses empreendimentos, indo da gestão coletiva, com possibilidades de maior autonomia e mesmo emancipação dos trabalhadores, à simples precarização do trabalho, com a eliminação dos direitos sociais vinculados ao 
assalariamento formal, que vem sendo tentado desde os anos 1990. Esse processo resultou do aumento do desemprego num contexto de políticas econômicas neoliberais, no qual o trabalho assalariado era visto como algo a ser eliminado, dado o chamado "custo Brasil", compreendido como perda da competitividade internacional.

O tema das fábricas recuperadas, ou empresas recuperadas pelos trabalhadores, situa-se dentro do debate mais geral sobre cooperativas de trabalho como opção de ocupação e geração de renda, debate que voltou à tona a partir dos anos 1980, num quadro de reestruturação econômica, com transformações tecnológicas e de gestão que tiveram como resultado a eliminação de qualificações, postos de trabalho e o aumento do desemprego.

Este artigo objetiva analisar os dilemas compreendidos na gestão coletiva, em fábricas recuperadas pelos trabalhadores no Brasil, organizadas, em sua maioria, na década de 1990. Essas fábricas foram estruturadas ora como cooperativas, ora como formas híbridas de gestão ${ }^{2}$ (Cf. Valle, 2002). Em geral, elas tiveram o apoio de sindicatos e progressivamente se inseriram no movimento de Economia Solidária que se institucionalizou na década seguinte. Após 20 anos do surgimento dos primeiros empreendimentos desse tipo, buscamos não só - verificar como eles se mantiveram no mercado e se adaptaram às mudanças político-econômicas do período, mas também analisar sua relação com as propostas originais de autogestão.

Os processos de recuperação, apesar de vinculados a propostas de propriedade e gestão coletiva, não tiveram como suporte um movimento organizado pelos trabalhadores em busca da autogestão, surgindo antes como uma resposta imediata ao desemprego, o que teria implicações no desenvolvimento posterior desses empreendimentos, que seriam obrigados a adequar-se às necessidades impostas pelo mercado como condição de sobrevivência, levando, muitas vezes, a uma redução do

${ }^{2}$ Cogestão ou autogestão. alcance da gestão coletiva. Independentemente dessas situações, no geral, esses empreendimentos são percebidos positivamente pelos trabalhadores que participaram da recuperação, pela melhora do clima organizacional, entendida como redução de hierarquias e maior participação nas decisões, além da maior estabilidade provida ao emprego. Entretanto, foi constatado que, na maioria das empresas, as novas adesões são restritas, preponderando a contratação de trabalhadores assalariados, o que, de certa forma, as torna similares a uma empresa regular, heterogestionária. Com isso, a gestão coletiva termina sendo reduzida aos trabalhadores participantes do processo de recuperação e não generalizada ao conjunto dos trabalhadores. Para os trabalhadores e para as empresas cooperativas, permanece o dilema, nem sempre explícito, da gestão coletiva versus integração no mercado, e as possibilidades efetivas de conciliá-las.

Foram analisadas dez fábricas recuperadas - sete do setor metalúrgico, uma do setor têxtil, uma do setor de plástico e uma mineradora -, a partir de visitas, entrevistas com gestores, trabalhadores e órgãos de apoio como Associação Nacional de Trabalhadores em Empresas de Autogestão e Participação Acionária (ANTEAG) e UNISOL Brasil (Central de Cooperativas e Empreendimentos Solidários), entre maio de 2011 e dezembro de 2013. A perspectiva foi longitudinal, recuperando majoritariamente empreendimentos iniciados na década de 1990 e referenciados nas incubadoras e em órgãos de apoio.

\section{A CRISE DOS ANOS 1990 E AS FORMAS ALTERNATIVAS DE EM- PREGO}

A reestruturação produtiva dos anos 1990 passou a questionar a relação salarial que se tornou onerosa para as empresas dentro do paradigma da flexibilidade de produtos, processos e mercados. A desregulamentação dos 
mercados de trabalho tornou-se objeto de políticas estatais a partir dos anos 1980 e 1990 em diversos países, embora com resultados distintos, marcando, todavia, uma tendência.

Na Europa, o crescimento do cooperativismo de trabalho vai estar vinculado a períodos de depressão econômica, havendo a organização de frentes de trabalho em cooperativas com apoio estatal variável de acordo com o contexto. A partir do final da década de 1930, a Igreja Católica irá apoiar o cooperativismo visto como uma possibilidade de frear o avanço comunista. Concomitantemente, no Brasil, a partir da década de 1930, o cooperativismo aparece cada vez mais como política estatal subordinada, tal qual o sindicalismo, a um Estado progressivamente mais regulador. O funcionamento de cooperativas rurais seria incentivado como contraposição aos conflitos pela terra e às lutas pela reforma agrária. Cada vez mais, a cooperativa passaria a ser percebida como uma forma de gestão vinculada ao mercado, sendo destituída de qualquer prática social emancipadora. Isso se evidencia no enfoque empresarial presente na Organização das Cooperativas Brasileiras (OCB) e suas seções estaduais.

Algumas pesquisas sobre cooperativismo de trabalho ressurgem no início dos anos 1980 na Europa, destacando, principalmente, as novas formas de organização da produção e o crescimento do desemprego estrutural. Ao lado do fechamento de fábricas e empresas diversas que são "recuperadas" como cooperativas, outras são organizadas numa perspectiva alternativa, como resposta às mudanças culturais da década de 1970, principalmente na Europa, nos Estados Unidos e no Canadá: cooperativas de alimentação alternativa, de cuidados específicos, de produtos naturais, escolas, livrarias etc. (Cornforth, 2007; Badstone, 1983; Taylor, 1994; Thornley, 1983).

No final dessa década, algumas cooperativas organizadas para a terceirização de atividades industriais aparecem na Espanha, vinculadas à Igreja Católica e a redes de lojas de confecções, e foram analisadas na pers- pectiva da industrialização difusa, produto da flexibilização da nova fase da industrialização e potencialmente positiva, tal como foi advogado por Piore e Sabel (1984). No início dos anos 1990, as cooperativas de confecções terceirizadas para grandes empresas representavam, em algumas regiões espanholas, mais de $10 \%$ da mão de obra ocupada no setor (Gutiérrez, 1992). Ainda na Espanha, o Complexo Cooperativo de Mondragón tornou-se referência sobre a possibilidade da organização cooperativa num contexto de internacionalização da produção e dos mercados. O Complexo, similar a um holding de empresas, em tese, mantém o caráter cooperativo em suas diversas unidades no País Basco Espanhol, o que não acontece em suas outras empresas mantidas no território espanhol e no exterior. Em etnografia realizada em Mondragón, Kasmir (1996) trata como mito o caráter autogestionário do complexo, destacando as hierarquias internas e também a contratação de trabalhadores assalariados. $\mathrm{Na}$ Itália, outro país com forte tradição cooperativista, as fábricas recuperadas cresceram com a reestruturação produtiva e se beneficiaram, num primeiro momento, com as relações políticas do governo com estados socialistas e simpatizantes (Baldacchino, 1990). Mais recentemente, Duaibs (2016) destaca que o sucesso econômico obtido pelas cooperativas italianas a partir de sua internacionalização produtiva precisa ser relativizado, e que, tal como o caso espanhol, apenas a empresa matriz se mantém cooperativa, enquanto as filiais, espalhadas por vários lugares do mundo, funcionam como empresas regulares heterogestionárias.

No Brasil, nos anos 1980, algumas experiências de cooperativas de trabalho foram relatadas a partir de pesquisas sobre fábricas em situação falimentar em alguns estados da federação, como no Rio Grande do Sul (Holzmann, 2001), Paraíba, Rio Grande do Norte, e também algumas experiências financiadas pela Interamerican Fundation, visando à geração de trabalho e renda entre populações carentes (Lima, 2002). Entretanto, será ape- 
nas nos anos 1990 que essas experiências se multiplicariam, assumindo maior visibilidade, recolocando o tema das cooperativas de trabalho e o debate sobre trabalho e autogestão no Brasil. Anteriormente, houve apenas experiências pontuais de fábricas cooperativas (Claro, 2004), e a discussão sobre o cooperativismo esteve restrito ao cooperativismo agrícola ou mesmo de crédito.

A partir de 1990, as cooperativas foram então organizadas dentro do que poderíamos classificar em três tipos gerais, seja como forma de combater o desemprego e promover geração de renda, seja como forma de reduzir custos empresariais através de redes de terceirização. No primeiro caso, situam-se as fábricas ocupadas por trabalhadores a partir de crises financeiras e ameaças de fechamento, geralmente apoiadas por sindicatos e ONGs, e cooperativas incubadas por núcleos vinculados a movimentos sociais e universidades, ambas com o objetivo de geração de renda. No segundo, há as chamadas endowment cooperatives (Cornforth, 2007), produto de um acordo com proprietários que passam para os trabalhadores parte das fábricas os quais trabalham terceirizados para a empresa. Ou ainda, cooperativas organizadas com esse objetivo incentivadas pelo Estado e por empresas a partir de políticas específicas de atração de investimentos industriais em regiões pouco industrializaते das e mesmo por sindicatos em acordos com empresas (Lima, 2008). No geral, essas últimas ฐี são consideradas cooperativas fraudulentas, ou falsas cooperativas, uma vez que, em sua \& organização, os princípios autogestionários do क movimento cooperativista - vínculo aberto e م \& voluntário, controle democrático por parte dos 今ं membros, participação econômica dos mem-

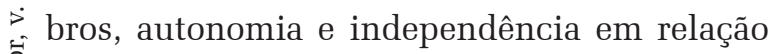
ao Estado e a outras organizações, compromisso com a educação dos membros, cooperação Fే entre cooperativas, contribuição para o desenvolvimento da comunidade em que está localizada a cooperativa - não estariam presentes, e seriam vistos apenas como subterfúgios para as empresas fugirem do contrato formal de trabalho assalariado. Essas progressivamente foram fechadas pelas delegacias do trabalho e Ministério Público, ou se adaptaram às normas cooperativistas.

Nessa tipologia, no primeiro caso, encontram-se as experiências que visavam a assessorar processos de recuperação de fábricas em situação falimentar e sua transformação em cooperativas de trabalhadores, ou a organização de cooperativas populares entre trabalhadores excluídos do mercado de trabalho (por idade ou qualificação) e populações de baixa renda. Esses empreendimentos resultaram, em sua maioria, de processos de recuperação e incubação por instituições como a ANTEAG, que surge em 1994 a partir da iniciativa de lideranças sindicais, a Unitrabalho, vinculada a uma rede de universidades, e a Cáritas, organização da Igreja Católica.

Essas entidades se articularam progressivamente em um movimento, que a partir do Fórum Mundial de 2001, em Porto Alegre, passou a se definir como "economia solidária", no qual as cooperativas desempenhariam um papel central. Sua proposta foi criar uma alternativa socialista diferente das experiências fracassadas do Leste Europeu. Um socialismo de mercado, alternativo ao mercado capitalista, no qual novas solidariedades fossem formadas através de distintas instituições e organizações sociais: trocas solidárias, banco popular, cooperativas, entre outros. Com isso, as cooperativas de economia solidária estariam vinculadas a propostas políticas de autonomia, democracia participativa nos locais de trabalho, autogestão e propriedade coletiva dos meios de produção, constituindo-se num tipo diferenciado das demais, um "novo cooperativismo" (Gaiger, 2004; Singer, 2002).

Nos anos 1990, o movimento citado acima cresce, sendo que, em 1999, a Central Única dos Trabalhadores (CUT) criou a Agência de Desenvolvimento Solidário (ADS), cuja finalidade era apoiar essas cooperativas através de assessoria na organização e mesmo manu- 
tenção de fábricas recuperadas e associações cooperativas. Diversas prefeituras e governos de estado, em sua maioria sob o controle do Partido dos Trabalhadores (PT) criaram suas secretarias de economia solidária.

A partir do primeiro governo Lula, em 2003, é criada a Secretaria Nacional de Economia Solidária (SENAES), e o cooperativismo torna-se política pública federal. Também em 2003, surge a UNISOL Brasil (Central de Cooperativas e Empreendimentos Solidários), ${ }^{3}$ com o objetivo de organizar, representar e articular as cooperativas, associações e outros empreendimentos autogestionários de economia solidária. Apesar de não limitar sua atuação junto a empreendimentos de produção industrial, a UNISOL Brasil passou a ser, juntamente com a ANTEAG, uma das principais instituições de apoio à criação e manutenção de fábricas recuperadas no país.

Vale a pena observar que esse movimento, no Brasil, teve um caráter distinto do movimento de fábricas recuperadas na Argentina, no contexto da crise enfrentada por aquele país no início dos anos 2000, quando houve um movimento de ocupação de empresas pelos trabalhadores (Allegrone; Partenio; Álvarez, 2004; Rebón; Saavedra, 2006). Embora os casos de recuperação de empresas na Argentina tenham um elevado crescimento a partir de 2002, há experiências de ocupação de fábricas ainda no final dos anos 1980. Se essa primeira “onda" de ocupações demonstrava um caráter defensivo, no sentido de manutenção dos postos de trabalho, as experiências que têm origem no início dos anos 2000 apresentam a proposta da gestão coletiva e ainda trazem novas demandas, como a necessidade de uma política pública orientada para o setor, direitos relacionados ao trabalho e políticas públicas orientadas para a industrialização nacional (Allegrone; Partenio; Álvarez, 2004).

Os processos de recuperação se difun-

${ }^{3}$ A UNISOL inicia suas atividades em 1999, como União e Solidariedade das Cooperativas do Estado de São Paulo (UNISOL São Paulo) e, em 2003, passa a atuar no nível nacional, passando a se chamar UNISOL Brasil. diram por todo o país, envolvendo mais de 10 mil trabalhadores e ensejando o primeiro movimento de empresas recuperadas: Movimiento Nacional de Empresas Recuperadas (MNER) (Rebón; Saavedra, 2006). Merece destaque ainda o fato de que, enquanto, no Brasil, os casos de recuperação de empresas estão restritos quase que exclusivamente ao setor industrial, temos, na Argentina, experiências de recuperação de empreendimentos do setor de alimentação (restaurantes, padarias, supermercados etc.), hospitais e clínicas de saúde, gráficas, empresas de serviços gerais (limpeza, manutenção de edifícios), escolas, entre outros (Fajn, 2004), reforçando a ideia de que a ocupação é uma forma de luta que tem certa legitimidade na cultura operária na Argentina, diferentemente do que observamos no Brasil (Pires, 2016). ${ }^{4}$

Portanto, no Brasil dos anos 1990, o cooperativismo inicia-se de forma pontual em fábricas em situação falimentar, não se constituindo a partir de um movimento. As fábricas-cooperativas contavam inicialmente com o apoio de sindicalistas, mas também enfrentavam fortes resistências sindicais, sendo percebidas como forma de precarização das relações de trabalho. Isso levanta alguns dos dilemas do cooperativismo de trabalho e a dificuldade de classificações rígidas entre o autêntico e o falso, entre precarização, autonomia e possibilidades de emancipação dos trabalhadores pela autogestão.

Um passo para a superação do caráter precarizante se deu com a promulgação da lei $n^{\circ}$. 12.690, de junho de 2012, que reformulou a legislação sobre cooperativismo de trabalho no Brasil, regulamentando e estabelecendo critérios mais claros para a relação entre a cooperativa, seus sócios e o mercado, com o objetivo de evitar a criação e manutenção de cooperativas fraudulentas. Entre as principais novidades da lei estão a determinação de um mínimo de sete sócios para a formalização da

${ }^{4}$ Outro país de destaque na organização de cooperativas é a Venezuela, a partir do governo Chaves. Sobre o movimento das fábricas/empresas recuperadas naquele país, ver Azzellini (2009). 
cooperativa (anteriormente eram vinte), a criação do Programa Nacional de Cooperativas de Trabalho (PRONACOOP) e a delimitação de direitos trabalhistas aos associados, como por exemplo, a obrigatoriedade de as cooperativas recolherem as taxas de previdência social.

Os primeiros estudos sobre fábricas recuperadas na década de 1990 (embora não exclusivamente) surgem na década seguinte, quando são analisados os processos de recuperação, com seus problemas e dilemas. Entre os pontos então destacados estão a gestão coletiva e suas dificuldades, os processos representativos, como a regularidade de assembleias, a participação efetiva dos trabalhadores, suas percepções sobre a democracia e os processos de trabalho, a questão sociotécnica, os problemas de financiamento e recuperação de mercados, a contratação de assalariados e a inovação representada pela gestão coletiva (ANTEAG, 2000; Esteves, 2004; Faria; Novas; Dagnino, 2008; Henriques, 2013; Juvenal, 2006; Novaes, 2007b; Paulucci, 2007; Valle, 2002; Vieitez; Dal Ri, 2001). No geral, essa produção destaca o caráter inovador do processo, ao garantir empregos e a busca por autonomia dos trabalhadores, variando o grau de entusiasmo e (ou) ceticismo sobre suas possibilidades. ${ }^{5}$

\section{OS PROCESSOS DE RECUPERA- ÇÃO E A FORMAÇÃO DE COOPE- RATIVAS}

\footnotetext{
A maior parte das experiências de fábricas recuperadas ${ }^{6}$ no Brasil surgiu entre o final dos anos 1990 e o início dos anos 2000. A adoção de políticas de orientação neolibei ral afetou profundamente o setor produtivo e as relações de trabalho. A elevação das taxas de juros, a desativação de políticas industriais e a rápida abertura econômica resultaram em

${ }^{5}$ Além disso, existe uma grande quantidade de teses e dissertações disponíveis na Capes com estudos de caso, ou casos, de diversas empresas, fábricas e cooperativas.

${ }^{6}$ Termo utilizado originalmente na caracterização da situação argentina.
}

desestabilização da economia, o que afetou, de maneira principal, o setor industrial. Assim, muitas empresas entraram em crise financeira, o que levou a diversos processos de falência e, consequentemente, muitos trabalhadores perderam seus empregos.

As transformações ocorridas na política econômica foram potencializadas por uma tendência de precarização do trabalho, tributária de um processo geral de reestruturação produtiva. É sabido que os países periféricos, como o Brasil, nunca tiveram um mercado de trabalho tão estruturado quanto os centrais, mas, ainda assim, sofreram os efeitos do processo de reestruturação, o que pode ser constatado por aumento das taxas de desemprego, diminuição do emprego formal, queda do valor real dos salários, aumento dos contratos de trabalho instáveis e da terceirização (Leite, 2009).

Diante de um cenário de aumento do desemprego, em que as chances de reinserção no mercado de trabalho eram restritas e as garantias do trabalho formal estavam ameaçadas, alguns grupos de trabalhadores se organizaram e se mobilizaram com o objetivo de assumir, coletivamente, a gestão das empresas em crise nas quais trabalhavam, como forma de manter seus postos de trabalho. Surgem as primeiras fábricas recuperadas, organizadas, sobretudo, no formato jurídico de cooperativas.

Os processos de recuperação foram marcados por percalços e dificuldades. Mesmo assim, várias fábricas recuperadas conseguiram se estruturar e continuam em atividade. Outras, no entanto, acabaram fechando as portas devido a questões jurídicas, dificuldades de acesso a mercados, defasagem tecnológica, falta de capital de giro e experiência em gestão. Nem todos os empreendimentos em recuperação aceitaram o formato da cooperativa, lutando por sua estatização, ou se transformando em empresa regular sob o controle de parte dos trabalhadores.

O movimento de recuperação perdeu força a partir da década de 2000 , com a retomada da economia e a maior formalização do merca- 
do de trabalho. A partir de 2003, tem início um movimento, capitaneado pelo governo federal, para reduzir os efeitos da reestruturação produtiva, incentivando o emprego formal, valorizando o salário mínimo e um conjunto de políticas sociais voltadas contra a precarização do trabalho e a eliminação da miséria. As cooperativas também foram beneficiadas por um conjunto de políticas de apoio ao cooperativismo de trabalho, com a criação da SENAES. Novas cooperativas foram organizadas, embora, entre elas, poucas fábricas, como foi demonstrado também por Henriques et al. (2013).

Com relação às fábricas que foram recuperadas pelos trabalhadores, distintas situações podem ser observadas após duas décadas de funcionamento a partir da amostra pesquisada. Na Tabela 1, podemos observar algumas características gerais das fábricas incluídas na amostra.

Tabela 1 - Fábricas pesquisadas

\begin{tabular}{|c|c|c|c|c|}
\hline $\begin{array}{l}\text { Fábrica } \\
\text { recuperada }\end{array}$ & Local & Ramo & $\begin{array}{l}\mathrm{N}^{\circ} \mathrm{de} \\
\text { sócios }\end{array}$ & $\begin{array}{c}\mathrm{N}^{0} \text { total de } \\
\text { trabalhadores }\end{array}$ \\
\hline Cooperminas & Criciúma (SC) & Mineração & 400 & 800 \\
\hline Bruscor & Brusque (SC) & Têxtil & 11 & 15 \\
\hline Coopermambrini & $\begin{array}{l}\text { Vespasiano } \\
\text { (MG) }\end{array}$ & Metalúrgica & 12 & 48 \\
\hline Cooparj & $\begin{array}{l}\text { Duque de } \\
\text { Caxias (RJ) }\end{array}$ & Metalúrgica & 20 & 20 \\
\hline Coopersalto & Salto (SP) & Metalúrgica & 49 & 88 \\
\hline Metalcoop & Salto (SP) & Metalúrgica & 51 & 83 \\
\hline Copromem & Mococa (SP) & Metalúrgica & 350 & 500 \\
\hline Uniforja & Diadema (SP) & Metalúrgica & 294 & 584 \\
\hline Unimáquinas & $\begin{array}{l}\text { São Bernardo } \\
\text { do Campo (SP) }\end{array}$ & Metalúrgica & 10 & 12 \\
\hline Flaskô & Sumaré (SP) & Plásticos & --- & 70 \\
\hline
\end{tabular}

Fonte: elaborado pelos autores (2014).

* Trata-se da soma do número de sócios com o número dos trabalhadores assalariados (contratados via CLT)

De uma forma geral, os processos de recuperação de empresas, no Brasil, seguiram uma trajetória similar. No contexto da crise, as empresas se endividaram, deixaram de pagar impostos e fornecedores bem como os salários e benefícios dos trabalhadores, que se mobilizavam através de paralizações na produção e greves. Diante dessa situação, os sindicatos se aproximaram dos trabalhadores, sendo, na maioria dos casos, os responsáveis por apresentar a alternativa da ocupação e gestão coletiva da empresa. Inicialmente, a $\mathrm{ANTEAG}^{7}$ e, depois, a UNISOL acompanhavam a maioria dos processos de recuperação (Henriques et al., 2013; Pires, 2014).

As próprias instituições de apoio às fábricas recuperadas não tinham uma metodologia de recuperação definida no início. A recuperação implicava a conversão das dívidas trabalhistas, na Justiça, no direito sobre instalações e maquinário que compunham a massa falida. Durante o processo judicial, ora o controle sobre a fábrica estava nas mãos dos trabalhadores, ora passava para as mãos dos antigos proprietários. Em muitos casos, o estabelecimento de um acordo ou a tomada de uma decisão definitiva levava vários anos, nem sempre com ganhos para os trabalhadores (Holzmann, 2001).

Em um dos casos, a Cooperminas - Cooperativa de Extração de Carvão Mineral dos Trabalhadores de Criciúma Ltda., localizada no próprio município de Criciúma (SC) - é uma das experiências pioneiras de recuperação, tendo iniciado seu processo em 1987, quando os trabalhadores começaram a ter seus salários atrasados e descobriram que a empresa que a originou vinha sonegando impostos e deixando de repassar direitos trabalhistas. A ANTEAG descreve o processo de recuperação da Cooperminas como um dos casos mais traumáticos já registrados de trabalhadores que lutaram para salvaguardar seus postos de trabalho (ANTEAG, 2000). Isso porque esse processo, que levou pelo menos dez anos, envolveu diversas tentativas de reintegração de posse dos antigos patrões, dificuldades financeiras

7 Mesmo não estando vinculada diretamente a sindicatos ou centrais sindicais, a ANTEAG se constituiu a partir da presença de sindicalistas e militantes próximos ao Sindicato dos Químicos de São Paulo. 
extremas, idas a Brasília, confrontos corpo a corpo com a polícia. Na época, os trabalhadores acamparam sobre os trilhos, impedindo o transporte de carvão de outras mineradoras e chegaram até mesmo a amarrar bananas de dinamite aos próprios corpos como forma de resistência na luta para manter o controle sobre a massa falida. $\mathrm{O}$ caso da Cooperminas pode ser considerado um dos processos de recuperação mais extremos, mas é representativo de tantos outros que envolveram paralisações, greves, acampamentos dos trabalhadores na porta das fábricas e confronto com a polícia.

A recuperação que levou à formação da Coopersalto - Cooperativa de Produção dos Metalúrgicos de Salto, fábrica do interior de São Paulo - também envolveu a formação de acampamento em frente à empresa como meio de pressionar o poder público a se posicionar sobre a questão do controle da massa falida. Por fim, em razão das disputas judiciais ocorridas com o antigo patrão, os trabalhadores não puderam permanecer no mesmo local onde estava instalada a antiga fábrica e buscaram outro local para a instalação da cooperativa. Percalços semelhantes também marcaram o início das atividades da Metalcoop - Cooperativa de Produção Industrial de Trabalhadores em Conformação de Metais, também localizada na cidade de Salto.

A Uniforja - Cooperativa Central de Produção Industrial de Trabalhadores em Metalurgia, localizada em Diadema (SP) - é uma das mais conhecidas experiências de recuperação. O processo contou com uma etapa de cogestão, isto é, uma forma de gestão partilhada entre proprietários e trabalhadores em que o voto é proporcional ao capital, a minoria do capital fica com os trabalhadores e a associação é a detentora das ações da empresa (Peixoto et al., 2002). No caso da Uniforja, a fase de cogestão durou dois anos, pois, as decisões tomadas em conjunto não eram devidamente implementadas pela empresa, o que aumentou o descrédito entre os trabalhadores. O fato é que a cogestão, inclusive em outros empreendi- mentos (Chaves, 2008; Esteves, 2004), parece se configurar como uma alternativa encontrada pelos patrões para "iludir" os trabalhadores, na medida em que eles são levados a aceitar essa condição diante da crise da empresa e como forma de minimizar conflitos; mas, na realidade, as decisões importantes continuam a ser tomadas pelas antigas camadas administrativas, e os trabalhadores têm pouco acesso às informações e uma participação muito restrita e controlada.

A Bruscor - Bruscor Indústria e Comércio de Cordas e Cadarços Ltda., empreendimento de Brusque (SC) - tem uma história que se diferencia das demais experiências de recuperação. A rigor, ela não é uma fábrica recuperada, visto que não surgiu a partir da falência de outra empresa, mas já iniciou suas atividades como empresa autogestionária. Seu projeto começou a ser idealizado ainda nos anos 1980, quando não havia outras experiências de recuperação e nem instituições que dessem suporte a esse tipo de iniciativa. Tratava-se de um grupo de amigos, pessoas vinculadas a partidos políticos de esquerda e a causas sociais, que buscavam constituir uma experiência de produção em que pudessem trabalhar juntos, sem explorar o trabalho alheio e de uma forma que lhes permitisse permanecer militando politicamente.

A Copromem - Cooperativa de Produtos Metalúrgicos de Mococa, localizada no município de Mococa (SP) e fabricante de produtos caldeirados para tratores e máquinas rodoviárias - surgiu a partir da falência da Nicola Rome Máquinas e Equipamentos S/A, em 1999, com o apoio do Sindicato dos Metalúrgicos de Mococa, após uma crise decorrente de mudanças no plano econômico e decisões administrativas equivocadas. Formalmente, a cooperativa formada pelos trabalhadores iniciou suas atividades no ano 2000.

Relativamente pacífico foi o processo de formação da Coopermambrini - Cooperativa Autogestionária dos Trabalhadores da Mambrini -, pelo menos no início de suas ativida- 
des. Essa fábrica de carrocerias de Vespasiano, região da Grande Belo Horizonte (MG), foi formada a partir da crise da empresa originária, quando os proprietários passaram o controle da fábrica para os funcionários, que negociaram o maquinário e as instalações em troca da dívida trabalhista.

A Unimáquinas - Cooperativa de Trabalho e Produção de Máquinas e Equipamentos, localizada em São Bernardo do Campo (SP) também teve uma transição relativamente pacífica para a autogestão. Trata-se de um caso diferente dos demais, por ser uma experiência descolada do contexto de recuperação das outras fábricas, isto é, sua recuperação é recente (a partir de 2009). Diante da situação de crise financeira, os antigos proprietários abandonaram a empresa, e alguns dos funcionários formaram a cooperativa com o apoio do Sindicato dos Metalúrgicos do ABC e da UNISOL Brasil.

Além da relação geralmente conflituosa com proprietários e administradores das fábricas originárias e dos tortuosos processos judiciais, os trabalhadores costumam enfrentar, nos primeiros anos do empreendimento, sérias dificuldades financeiras: problemas para obter financiamentos e ter de produzir com equipamentos obsoletos e degradados (em razão da crise financeira da empresa anterior). As empresas, com dívidas relativas ao não recolhimento de impostos e tributos, não conseguiam acesso a linhas de crédito (Valle, 2002). Sem crédito, torna-se difícil adquirir matérias-primas e investir em novos equipamentos e novas tecnologias. Além disso, a nova empresa carrega a imagem da empresa falida com todos os seus problemas. Assim, obter a confiança de novos clientes, bem como restabelecer relações comerciais com os antigos, não se constitui em tarefa fácil.

Para auxiliar nesses primeiros passos, os sindicatos, bem como as instituições de apoio, desempenham um papel fundamental. Em uma situação de crise e ameaça de demissão em massa de qualquer empresa, são primeiramente os sindicatos que se aproximam dos trabalhadores para entender a questão e buscar alternativas. O papel das instituições de apoio como ANTEAG e UNISOL Brasil, no caso aqui pesquisado, foi o de transmitir conhecimentos sobre como administrar a empresa, auxiliar nos contatos com fornecedores, prover apoio contábil e jurídico para a formalização do empreendimento e intermediar o acesso a crédito, principalmente via Banco Nacional de Desenvolvimento Econômico e Social (BNDES). Muitas empresas só conseguiram se estruturar a partir de financiamentos do BNDES que lhes possibilitaram capital de giro e compra de instalações e maquinários necessários para retomar e (ou) dinamizar a produção. Dentre esses empreendimentos, alguns tiveram apoio da ANTEAG, outros da UNISOL, e outros ainda de ambas, isto é, inicialmente da ANTEAG e depois da UNISOL Brasil.

Entretanto, nem todos os empreendimentos que passaram por processos de recuperação seguiram o modelo de cooperativas. Algumas se tornaram empresas regulares, geridas inicialmente pelo grupo que permaneceu, e obtiveram apoio da OCB em termos de consultoria. Outro grupo veio a configurar o Movimento das Fábricas Ocupadas, que recusou a via do cooperativismo e não buscou o apoio de nenhuma das instituições mencionadas. Seus trabalhadores entenderam que as cooperativas, na medida em que flexibilizavam os direitos trabalhistas associados ao assalariamento, favoreceriam a precarização do trabalho, tornando-se funcionais ao capitalismo. Assim, a proposta original era a estatização desses empreendimentos, mantendo a relação de assalariamento. Desse grupo, apenas uma empresa sobreviveu, a Flaskô - Flaskô Embalagens Industriais Ltda., fábrica do setor de plásticos localizada em Sumaré (SP) -, que é gerida pelo coletivo de trabalhadores através de uma associação cujos trabalhadores permanecem assalariados (Araújo, 2015; Leite et al., 2015; Raslan, 2007).

Ainda em outro caso, a história do Movimento das Fábricas Ocupadas tem início no 
ano de 2002, em Joinville, com greves e paralisações na Cipla (Companhia Industrial de Plástico). A Cipla, assim como a Interfibra, empresa também de Joinville que produzia tubos de epóxi para prospecção de petróleo, pertencia ao Grupo Hansen, que, após um processo de divisão, transformou-se na Corporação Hansen Batschauer, que passou a incluir, além da Cipla e da Interfibra, a Profiplast, a Brakofix (todas de Joinville, SC) e a Flaskô (de Sumaré, SP) (Paulucci, 2007). Nos anos 1990, essas empresas começaram a enfrentar problemas (defasagem tecnológica, não pagamento do FGTS dos funcionários, bem como de fornecedores e atraso de salários). $\mathrm{O}$ antigo proprietário passou então o controle da Cipla e da Interfibra para os trabalhadores, que iniciaram um movimento pela estatização, ao qual se juntou a Flaskô, ocupada em 2003. Em seguida, outras empresas ocupadas se juntaram ao grupo (Flakepet, em Itapevi, SP; Protiplast, em Joinville, SC; Ellem Metal, em Caieiras, SP). A Flakepet, a Protiplast e Ellem Metal não conseguiram prosseguir com suas atividades sob a gestão coletiva dos trabalhadores (problemas jurídicos e processos de intervenção). Em 2007, houve uma intervenção federal policial na Cipla e na Interfibra, e vários trabalhadores foram demitidos por justa causa. O interventor também foi a Sumaré, mas lá foi expulso A da Flaskô, que mantém a gestão coletiva e ainda resiste à transformação em cooperativa (Flaskô, 2013). ${ }^{8}$

을 Assim, os diversos processos de recuperação citados evidenciam a diversidade assu\& mida pelas empresas e seu sucesso relativo em s. \& to, além de demorado, mesmo com a consoli§ं dação, os desafios da manutenção do caráter coletivo da propriedade e sua gestão marcam os caminhos trilhados por esses empreendimentos.

${ }^{8}$ Informações mais recentes (2015) apontam a sua organização como cooperativa.

\section{A GESTÃO COLETIVA E A PARTICI- PAÇÃO}

Em geral, as fábricas recuperadas se consideram ou são consideradas pelo movimento da Economia Solidária como autogestionárias. No entanto, alguns autores (Faria, 2009; Guimarães et al., 2006) questionam a utilização do adjetivo "autogestionários" para caracterizar os empreendimentos cooperativistas. Para essa vertente, a origem do conceito de autogestão está relacionada a uma forma de organização social, ou seja, seria possível falarmos em uma sociedade autogestionária, mas não em empreendimentos autogestionários, visto que eles estão inseridos no mercado capitalista. Assim, a chamada "autogestão" seria restrita, parcial, não podendo ir além dos limites do próprio empreendimento. O fato é que as fábricas recuperadas estudadas criaram mecanismos que buscam possibilitar a gestão coletiva com uma maior participação do conjunto dos trabalhadores nas decisões, embora estejam longe da autogestão como um processo emancipatório. Mesmo que não sejam subordinados a um patrão, o mercado mantém a subordinação a seus ditames, impedindo sua superação.

Isso não significa que não se efetive uma maior democratização e controle coletivo da gestão. Em geral, há uma diretoria, ou um conselho administrativo, que representa o coletivo dos sócios e é responsável pela administração do dia a dia das fábricas. Esse grupo gestor é eleito em assembleia geral e tem um tempo de mandato definido. Os estatutos dos empreendimentos é que definem as regras de rotatividade dos membros que compõem os cargos de direção. Em tese, as assembleias gerais, que reúnem todos os trabalhadores cooperados, constituem-se no espaço mais importante de tomada de decisões e participação coletiva. Além do conselho de administração, algumas dessas empresas contam ainda com outros conselhos para fiscalizar e (ou) auxiliar a gestão, o que também é definido de acordo com o estatuto de 
cada empreendimento. Como isso se configura na prática é o que analisaremos a seguir.

Um primeiro obstáculo à gestão coletiva é o grande número de sócios. Os empreendimentos menores costumam ter uma estrutura administrativa mais simplificada, tendo mais facilidade em reunir a totalidade dos sócios para a tomada de decisões conjuntas e, assim, conseguem flexibilizar as regras que determinam a periodicidade de reunióes ou assembleias. Em fábricas recuperadas como a Bruscor, a Coopermambrini, a Cooparj e Unimáquinas, todas com menos de 20 sócios, embora exista uma diretoria que formalmente responde pelos empreendimentos, as decisões eram tomadas pelo conjunto dos sócios, que se reuniam de acordo com as necessidades do dia a dia, sem a necessidade de assembleias formais regulares. Nessas fábricas, também fica menos evidente a separação entre concepção e execução do trabalho.

Como aponta Simmel (1983), o crescimento de qualquer grupo necessariamente diminui a interação entre seus membros e passa a exigir órgãos ou instâncias representativas para sua manutenção. Assim, em cooperativas com grande número de trabalhadores, como a Cooperminas, a Copromem e a Uniforja, não é possível reunir o coletivo de sócios com facilidade. A fala de uma liderança da Cooperminas demonstra a dificuldade em conscientizar sobre as características do cooperativismo quando o número de trabalhadores é muito grande:

Ainda eu digo que existe meia dúzia de pessoas que têm o espírito antigo de cooperativa, que entende o passado e consegue segurar, porque o pessoal novo que vem hoje, você contrata porque precisa e tu não sabe a origem. Ele está precisando de emprego, mas, na hora, a coisa é diferente, por isso é preciso ter uma cobrança forte em cima disso. Nós temos um número muito grande de cooperados, se fosse um número menor seria mais fácil de controlar; 400 cooperados é muito difícil, um grupo menor é mais fácil de explicar.

A Cooperminas tem cerca de 400 sócios e um total de 800 trabalhadores. O número de tra- balhadores, tanto na Copromem como na Uniforja, é superior a 500. Em empreendimentos desse porte, as assembleias ordinárias ocorrem apenas duas ou três vezes no ano. A maior parte das decisões acaba ficando a cargo do grupo que compõe a administração, e as assembleias servem mais ao propósito de divulgação de resultados, distribuição de sobras (o que costuma ocorrer uma vez por ano) e legitimação do coletivo em relação a escolhas e procedimentos já adotados. Dessa forma, ainda que a participação dos trabalhadores nas assembleias seja quantitativamente significativa, a qualidade dessa participação é restrita. É preciso reconhecer, no entanto, que os trabalhadores das fábricas recuperadas, de uma maneira geral, consideram que, comparando a situação anterior à recuperação, possuem maior liberdade de circular no espaço do empreendimento, acessar seus superiores hierárquicos, sugerir mudanças e melhorias nos procedimentos, além de uma flexibilidade maior em relação a faltas e horários.

Apesar da formalização de regras que delimitam a duração dos mandatos e estabelecem a rotatividade dos cargos de direção, percebe-se que, em quase todas as cooperativas, há uma tendência de que um mesmo grupo de sócios permaneça na direção do empreendimento por vários anos. Em geral, esse grupo é formado por sócios que estão na cooperativa desde o início, isto é, que enfrentaram e, na maioria das vezes, tiveram um papel central na organização coletiva e no processo de recuperação. Em geral, as normas que estabelecem a rotatividade nos cargos de direção possibilitam que ocorra apenas uma substituição parcial dos membros dos conselhos administrativos, permitindo um rodízio dentro de um mesmo conjunto de sócios. Assim, os trabalhadores que centralizam a administração dos empreendimentos não têm a confiança de que os sócios que chegaram à fábrica depois de estabelecida a gestão coletiva dos trabalhadores saberão manter a proposta autogestionária. Há, portanto, uma insegurança em relação à compreensão e interiorização dos princípios cooperati- 
vistas pelos trabalhadores. A seguir, a fala de um dos membros da diretoria da Cooperminas ilustra essa insegurança, encontrada também entre as lideranças de outras fábricas:

\begin{abstract}
No início, em 1987, quando começou, o pessoal faliu e recomeçou tudo, foi uma conquista forte, a coisa ficou muito próxima e depois, com a rotatividade do pessoal, a coisa foi saindo fora, foi mudando ao longo desses anos. Nós, que somos mais velhos, temos que ir puxando, organizando, porque a grande maioria pensa no pagamento, é só direitos, os deveres não querem cumprir, então tem uma fiscalização grande em cima, de cobrar, chamar a atenção, senão a cooperativa se acaba. Esse sonho de 1987 se acaba, pela rotatividade grande e o não espírito de vontade de resolver do pessoal, de fazer sua parte, se não tomar cuidado... Ainda eu digo que existe meia dúzia de pessoas que têm o espírito antigo de cooperativa, que entende o passado e consegue segurar.
\end{abstract}

A ambiguidade desta fala aparece na necessidade do controle para que os trabalhadores entendam que a cooperativa não traz apenas direitos, mas deveres. Ou seja, a fábrica, para funcionar, depende que cada um cumpra sua parte, e, para esse membro da diretoria, apenas os mais velhos que participaram da luta pela recuperação entendem o que é cooperativa, e não apenas o pagamento no final do mês.

A formação constante para a autogestão seria uma condição necessária para a manutenção do trabalho cooperativo, mas a própria ₹ lógica concorrencial do capitalismo dificulta స essa prática. Além disso, a inserção na lógica autogestionária requer uma mudança cultural ธี่ muito ampla por parte de trabalhadores (Valle et al., 2002). Em geral, o trabalho é entendido \& como trabalho assalariado com carteira assina$\dot{2}$ $\stackrel{2}{\circ}$ da e direitos sociais, individualizado, subordiद. nado, com separação entre concepção e execuहे ção, assim como responsabilidades compartilhadas. Com isso, parte dos trabalhadores não entende que a condição e as responsabilidades de sócios são distintas daquelas que tinham Fi quando eram empregados. Os depoimentos de alguns cooperados ilustram essa dificuldade:

A maioria [...] vai trabalhar em uma fábrica, ser empregado e [...] sem essa noção de que (na cooperativa) seriam responsáveis por altos e baixos, aí começou a complicar. Porque aí dois ou três tinham essa visão e meia dúzia não tinha, daí começam as pequenas discussões (cooperada da Bruscor).

Entender a questão do cooperativismo autogestionário, participação, enquanto sócios do negócio é difícil. Nós, trabalhadores, temos uma cultura de sermos empregados, e, em um determinado momento de nossa história, dormimos como empregados e acordamos como sócios do próprio negócio [...]. Então, precisamos preparar essas pessoas que vêm trabalhar na cooperativa pra essa nova forma, esse novo conceito (sócio e ex-presidente da Metalcoop). As pessoas estavam acostumadas com uma cultura em que eram empregadas, tinham um patrão e, da noite pro dia, surge na cabeça dele que ele é dono. Muitas pessoas têm dificuldade de assimilar isso, acha que porque é dono pode fazer o que quiser, vir trabalhar quando quiser, e, na verdade, não é assim, a cooperativa tem suas regras (trabalhador associado da Copromem).

Com isso, as direções tendem a permanecer com o mesmo grupo de cooperados, sendo justificadas pelo desinteresse ou pouco envolvimento de outros cooperados. Essa resistência em incentivar que outros trabalhadores assumam postos de direção aparece também no momento em que surge a discussão sobre a possibilidade de incorporar novos sócios para as cooperativas. Em geral, os novos sócios passam da condição de empregados à de associados, processo que tem uma normatização diferente em cada fábrica, mas que costuma ocorrer do seguinte modo: o trabalhador permanece por determinado tempo como funcionário e, ao fim desse período, se for de sua vontade e de interesse da cooperativa, ele pode pagar uma quota e entrar para a sociedade. No entanto, até mesmo em razão da falta de compreensão sobre o cooperativismo e em função de experiências negativas enfrentadas por alguns dos empreendimentos, esse mecanismo não é colocado em prática com frequência, embora seja o desejo de vários empregados:

No início, a pessoa entrava para trabalhar, dava a experiência dela e automaticamente já se tornava cooperado. Só que a pessoa, quando empregada, 
era exemplar, mas, quando se tornava cooperado, confundia e começava a ser o pior cooperado. Aí foi criada uma regra que, para se tornar cooperado, tem que ser, no mínimo, colaborador por três anos, passa por uma comissão que vai avaliar juntamente com o coordenador, pesquisando com os companheiros de setor dele (cooperado da Copromem).

A gente teve problema em uma das cooperativas com funcionário bonzinho, excelente que virou um satanás [quando se tornou cooperado]. Então eu fico com o pé atrás, só isso. Eu sempre falei assim: "é muito fácil você entrar em uma casa mobiliada, com tudo prontinho.” (cooperado da Uniforja).

Em geral, quando pensamos no cooperativismo, talvez a tendência seja entendê-lo como uma forma de inserção precária no mundo do trabalho. Quando lidamos com cooperativas populares, como as de reciclagem, terceirização de serviços (como limpeza) e de costura (facções), fica evidente a insegurança dos trabalhadores e suas perspectivas sempre se orientam no sentido de sair da condição de cooperados e encontrar um trabalho "com carteira assinada” (Pires, 2010). Já nas fábricas recuperadas, sobretudo aquelas que se encontram em uma posição consolidada no mercado, os sócios se sentem mais seguros na condição de cooperados, mais até do que em uma condição de trabalho assalariado formal, embora haja o questionamento de que o assalariado, muitas vezes, tem mais direitos que os cooperados. Entretanto, a tendência dessas fábricas é a de contratar empregados, justificando pela sazonalidade da produção, o que com cooperados seria inviável.

O assalariamento é uma relação de subordinação que compromete o ideal igualitarista do cooperativismo. Como podemos observar na Tabela 1, o número de sócios é menor do que o número total de trabalhadores nas fábricas aqui estudadas, com exceção da Cooparj e da Flaskô. Nos casos da Cooperminas, da Coopersalto e da Uniforja, o número de contratados é o mesmo (ou praticamente o mesmo) que o número de cooperados. No caso da Coopermambrini, o número de contratados equivale ao triplo do número de sócios e os primeiros costumam ter uma remuneração inferior à dos sócios que ocupam funções semelhantes, porém contam com os direitos trabalhistas. Os sócios, em contrapartida, participam da divisão de sobras (quando há) e, em muitos empreendimentos, possuem alguns benefícios análogos ao décimo terceiro salário, férias remuneradas, entre outros.

Vale destacar que, nas fábricas recuperadas, tal como acontece nas empresas comuns, a remuneração dos trabalhadores depende da função exercida e, portanto, da qualificação. No entanto, em relação à empresa original, as fábricas recuperadas procuram diminuir as diferenças de remuneração. Nas fábricas menores, as diferenças de remuneração entre os sócios, e mesmo entre sócios e funcionários, costumam ser menores. Nas empresas maiores, essa situação é mais variável. Na Coopersalto, Metalcoop e Copromem, é estabelecida uma diferença máxima entre as remunerações, de forma que o valor da maior não supera cinco vezes o valor da menor. Na Uniforja, essa diferença fica na proporção de dez para um. As fábricas recuperadas, de maneira geral, também tendem a simplificar a hierarquia, diminuindo o número de níveis hierárquicos, comparando-se com a empresa original.

\section{A CONSOLIDAÇÃO E OS PROBLEMAS}

A partir de meados dos anos 2000, passamos a vivenciar uma situação de maior estabilidade econômica, com crescimento do emprego formal e queda do número de falências. Além disso, em 2005, passou a vigorar a nova lei de falências, que também parece ter inibido novos processos de recuperação. A lei $n^{\circ}$ 11.101 alterou a ordem de quitação de débitos com os credores, de forma que as dívidas trabalhistas deixaram de ser prioridade absoluta. Portanto, a nova regulamentação dificulta possíveis iniciativas dos trabalhadores em assumir o controle de empresas em situação falimentar, na medida em que não prevê que 
eles possam optar pela troca de seus créditos trabalhistas pelos bens da empresa, além de não possibilitar o arrendamento da empresa pelos trabalhadores sem que, para isso, eles assumam a dívida anterior (Silva, 2005).

Com isso, percebemos que, no Brasil, os processos de recuperação vinculam-se a uma situação de crise geral, sendo acionados para salvar postos de trabalho quando outras formas de inserção no mercado de trabalho são limitadas ou praticamente inexistentes, embora com exceções. Nisso, o caso brasileiro parece se diferenciar da experiência Argentina, por exemplo, em que a recuperação parece fazer parte do "repertório" da cultura operária, na medida em que, naquele país, pelo menos a partir de 2000, a "tomada" ou "ocupação" da empresa parece ser um artifício comumente utilizado pelos trabalhadores diante de uma situação iminente de falência da empresa.

Ainda que observemos uma sensível queda do número de recuperações no Brasil, elas não são completamente inexistentes, como comprova o caso da Unimáquinas. Ainda assim, esses casos mais pontuais estão geralmente associados à atuação da UNISOL Brasil e do Sindicato dos Metalúrgicos do ABC (à qual ela está ligada). Em 2014, existiam 21 fábricas recuperadas vinculadas à UNISOL, ${ }^{9}$ as quais estavam localizadas em cinco estados brasileiros (São Paulo, Rio Grande do Sul, Santa Catarina, จे Bahia e Minas Gerais) e eram pertencentes a diversos setores econômicos (têxtil, metalúrgico, สี่ químico e elétrico). No entanto, como apontou क a própria UNISOL, a defasagem tecnológica e \& a concorrência internacional, sobretudo com o i.

${ }^{9}$ Segundo Henriques et al. (2013), em levantamento realizado em 2012, haveria em torno de 67 fábricas recuperadas no país. estão distantes de ter a mesma capacidade das empresas convencionais (ou capitalistas) de acessar crédito público e privado.

A própria ANTEAG, apoiadora de processos de recuperação, vinha enfrentando muitas dificuldades financeiras nos últimos anos, passando a atuar mais em projetos locais (Região Metropolitana de São Paulo) de economia solidária, relacionados ao cooperativismo popular ${ }^{10}$. Durante nossa pesquisa, das fábricas apoiadas pela ANTEAG, a Bruscor vinha tentando se restabelecer após uma crise propiciada pela saída de alguns sócios em um passado recente. Peculiar, no entanto, era a situação da Coopermambrini. Essa cooperativa, após um processo de recuperação marcado por idas e vindas, conseguiu se restabelecer e vinha retomando uma posição de destaque no mercado, quando seus trabalhadores optaram pela venda da fábrica para um grupo privado. A Cooperminas continua em atividade, passando, inclusive, por um processo de expansão e modernização. Em geral, a situação de mercado das outras fábricas visitadas apoiadas pela UNISOL Brasil era de estabilidade.

A Flaskô, como mencionamos, é a única fábrica do Movimento das Fábricas Ocupadas que segue sob o controle coletivo dos trabalhadores. Ao optar por não aderir à proposta do cooperativismo, a Flaskô não se vinculou nem à ANTEAG, nem à UNISOL. Assim, tornou-se uma experiência isolada. Hoje, o empreendimento segue em atividade, porém enfrentando diversos obstáculos jurídicos e dificuldades em termos de produção e comercialização de seus produtos.

As fábricas recuperadas não têm e nunca tiveram, assim como o conjunto dos empreendimentos da economia solidária, uma participação significativa no conjunto da economia do país, mas preservam uma significativa importância simbólica, na medida em que são frutos de resistência coletiva dos trabalhadores

10 A ANTEAG encerrou definitivamente suas atividades em 2014, de acordo com informações obtidas junto às lideranças da instituição. 
na busca por alternativas econômicas ou manutenção de postos de trabalho. Isso não significa, no entanto, que uma transformação social mais ampla tem ocorrido a partir dessas iniciativas, horizonte vislumbrado pelo movimento da economia solidária. Percebemos que, mesmo no interior dos empreendimentos, manter as práticas igualitárias e a autonomia na organização do trabalho exige um grande esforço para criar uma nova cultura do trabalho, na qual desaparece o trabalhador assalariado e surge o sócio trabalhador.

Além disso, o mercado, a todo o momento, impõe suas regras de produtividade, qualidade e competição, comprometendo seriamente a autonomia dos empreendimentos em decidir como organizam o trabalho, a produção e as relações no interior da fábrica. As fábricas recuperadas, assim como qualquer fábrica, impõem a seus trabalhadores um ritmo e uma dinâmica de trabalho que permitam cumprir as metas de produtividade. Além disso, elas não podem definir os preços de seus produtos de acordo com suas restrições produtivas ou sua lógica de justiça e igualitarismo, mas precisam operar preços semelhantes aos de suas concorrentes, ou são excluídas, isto é, têm de se inserir na lógica da competição para conseguirem ampliar seu mercado. Ainda precisam seguir normas e padrões específicos em termos de organização da produção para conseguir certificações de qualidade (como os ISO $^{11}$ ), sem as quais seus produtos não são aceitos no ciclo de produção industrial.

Se a maioria das fábricas em foco conseguiu obter certo sucesso econômico e certa estabilidade é porque se inseriram na lógica econômica capitalista, isto é, "entraram para o jogo”. Sua produção depende de matérias-primas produzidas e comercializadas por empresas não solidárias, não autogestionárias, assim como seus produtos são comercializados para

${ }^{11}$ ISO é a sigla para International Organization for Standardization, ou, em português, Organização Internacional para Padronização. Trata-se de uma entidade de padronização e normatização, criada em 1947, na Suíça, com o objetivo de estabelecer normas internacionais em todos os campos técnicos, de forma a garantir a qualidade permanente. parceiros capitalistas. Com todas as exigências em termos de produção e comercialização dos produtos, torna-se difícil realizar uma formação constante para a autogestão e para o cooperativismo, isto é, transmitir e apreender valores relacionados ao trabalho e participação coletiva, que permitiriam aos empreendimentos práticas mais democráticas e igualitárias.

Ainda assim, é preciso reconhecer que, de forma geral, as fábricas recuperadas buscam, na medida do possível, manter viva a ideia da autogestão como um processo a ser alcançado através da gestão coletiva e de práticas que visem, se não à supressão, pelo menos à redução de desigualdades no processo de trabalho.

\section{CONCLUINDO}

Os dilemas enfrentados por esses empreendimentos, que podem ser agrupados na aparente contradição entre gestão coletiva versus inserção no mercado, devem ser qualificados para sua compreensão. Por se constituírem em uma alternativa ao desemprego frente à crise da empresa, sua recuperação tem um caráter pragmático, que passa ao largo das proposições políticas de eliminação da subordinação da heterogestão. Tornam-se uma alternativa para um número reduzido de trabalhadores que permaneceram na ocupação da fábrica e que a recuperaram. Mesmo com a utilização das mesmas máquinas e os mesmos processos de trabalho, inovações organizativas são implementadas, como redução de hierarquias e participação na gestão.

O crescimento do empreendimento, por sua vez, exige que essa participação se dê por canais formais de representação, aumentando sua burocratização e, consequentemente, uma menor sensação de participação por parte dos trabalhadores. No Brasil, essa situação ainda é excepcional, considerando-se que a maioria das empresas é pequena ou média. Sazonalidades de aumento ou redução da produção 
resultam na contratação de assalariados. Em alguns casos, existem políticas de tornar esses assalariados sócios, mas são casos isolados. As demais tendem a criar uma dualidade dentro da fábrica entre os sócios e os empregados. Em algumas situações, o sócio se considera em situação subalternizada frente aos empregados, que possuem direitos e se regem pela CLT, mas isso é compensado pela estabilidade de que os contratados não desfrutam.

Concordando com Henriques et al. (2013), essas empresas seguem a lógica capitalista e não teria como ser diferente. Mesmo a Flaskô - que se considera mais um movimento do que um empreendimento - vende sua produção para o mercado e compete nesse mercado. Assim, discutir esses empreendimentos como parte de outra lógica, seria um esforço desnecessário, além de inútil. A diversidade dos empreendimentos, assim como das formas de participação dos trabalhadores, possibilita entendermos sua dinâmica, ora na direção de maior democratização das relações de trabalho, constituindo-se em modelos alternativos de gestão, ora em sua transformação, na qual os princípios cooperativistas se chocam com interesses dos sócios e da propriedade.

Várias experiências aqui apresentadas continuam ativas por mais de 20 anos, situação comum em outros países nos quais estão muito bem (Mondragón é o caso exemplar). స São casos pontuais e diversos e que continuam acontecendo, mesmo que em ritmo menor, 뜰 dado o crescimento econômico e do emprego formal no período 2003-2013, encerrados com \&े a crise de 2014. Esses empreendimentos se क. Constituem numa alternativa pragmática à in-

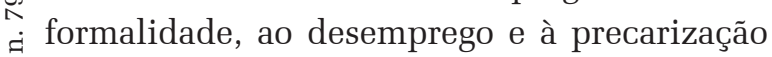
iे do trabalho, algo que tende a aumentar com as $>$ mudanças políticas e econômicas do país. Tal situação pode reverter a tendência de declínio dos últimos anos.

Recebido para publicação em 15 de outubro de 2015 Aceito em 14 de dezembro de 2016

\section{REFERÊNCIAS}

ALLEGRONE, V. G.; PARTENIO, F.; ÁlVAREZ, M. I. F. Los procesos de recuperación de fábricas: una mirada retrospective. In: BATTISTINI, O. R. (Org.). El trabajo frente al espejo: continuidades y rupturas en los procesos de construcción identitaria de los trabajadores. Buenos Aires: Prometeo, 2004

ANTEAG. Autogestão: construindo uma nova cultura de relações de trabalho. São Paulo: ANTEAG, 2000.

ARAÚJO, A. M. C. O Caso da Flaskô: uma proposta de estatização e controle operário. In: LEITE; M. de P.; ARAÚJO, A. M. C. ; LIMA, J. C. (Org.). O trabalho na Economia solidária: entre a precariedade e a emancipação. São Paulo: Annablume. 2015, p. 279-299.

AUED, B. W. Fábricas recuperadas e estatização. In: CONGRESO DE LA ASOCIACIÓN LATINOAMERICANA DE SOCIOLOGÍA. ASOCIACIÓN LATINOAMERICANA DE SOCIOLOGÍA, 26., Guadalajara, 2007. Anales... Guadalajara: [S.l.], 2007.

AZZELLINI, D. Economía solidaria, formas de propiedad colectiva, nacionalizaciones, empresas socialistas, co- y autogestión en Venezuela. Org \& Demo, Marília, Brasil, v. 10, n. 1-2, jan./dez., 2009.

BADSTONE, E. Organization and orientation: a life cycle model of french co-operatives. Economic and industrial democracy, v. 4, p. 139-161, 1983.

BALDACCHINO, G. War of position: ideas on a Strategy for worker cooperative development. Economic and industrial democracy, v. 11, p. 463-482, 1990.

CASTEL, R. As metamorfoses da questão social: uma crônica do salário. Petrópolis: Vozes, 1998.

CHAVES, L. C. Laboratórios sociais de autogestão no Brasil e na Argentina: cooperativas na produção e reprodução da vida em cooperação. 2008. 237 f. Tese (Doutorado em Sociologia Política) - Centro de Filosofia e Ciências Humanas, Universidade Federal de Santa Catarina, Florianópolis, 2008.

CLARO, M. Unilabor: desenho industrial, arte moderna e autogestão operária. São Paulo: Editora Senac, 2004.

CORNFORTH, C. Alguns fatores que afetam o sucesso ou o fracasso de cooperativas de trabalho: uma revisão das pesquisas empíricas no Reino Unido. In: LIMA, J. C. (Org.). Ligações perigosas: trabalho flexível e trabalho associado. São Paulo: Annablume, 2007. p. 19-54.

DUAIBS, R. Exxito ou revés? O dilema das cooperativas que prosperam. 2016. Tese (Doutorado em Ciências Sociais) Instituto de Filosofia e Ciências Humanas, Universidade Estadual de Campinas, Campinas, 2016.

ESTEVES, E. G. Sócio, trabalhador, pessoa: negociações de entendimentos na construção cotidiana da autogestão de uma cooperativa industrial. 2004. 177 f. Dissertação (Mestrado em Psicologia) - Instituto de Psicologia, Universidade Estadual de São Paulo, São Paulo, 2004.

FAJN, G. Fábricas Recuperadas: la organización en cuestión. 2004. Disponível em: <http://www.iisg.nl/ labouragain/documents/fajn.pdf $>$. Acesso em: 20 out. 2012.

FARIA, J. H. de. Relações de poder e de trabalho nas organizações. São Paulo: Atlas, 2009.

FARIA, M. S. de. “... se a coisa é por aí, que autogestão é essa?” Um estudo

da experiência "autogestionária" dos trabalhadores da Makerli Calçados. 1997. 233 f. Dissertação (Mestrado em Administração) - Universidade Federal de Santa Catarina, Florianópolis, 1997. 
; NOVAES, H. T.; DAGNINO, R. Do fetichismo da organização e da tecnologia ao mimetismo tecnológico: os labirintos das fábricas recuperadas. Revista Katálisys, Florianópolis, v. 11, n. 1, p. 123-131, jan. /jun. 2008.

FLASKÔ. Cronologia do movimento: 2002-2012. 2013. Disponível em: <http://www.fabricasocupadas.org.br/site/

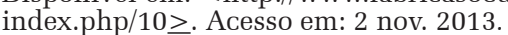

GAIGER, L. I. A economia solidária e o projeto de outra mundialização. Dados, Rio de Janeiro, v. 47, n. 4, p. 799834, 2004.

GUIMARÃES, V. N. et al. Empreendimentos autogeridos em Santa Catarina: uma alternativa democrática à produção. In: PICCININI, V. et al. (Org.). O mosaico do trabalho na sociedade contemporânea. Porto Alegre: Editora da UFRGS, 2006.

GUTIÉRREZ, A. C. M. Workers cooperatives: are they intrinsically inefficient? Economic and industrial democracy, v. 13, p. 431-436, 1992.

HARVEY, D. Condição pós-moderna. São Paulo: Loyola, 1993

HENRIQUES, F. C. Empresas recuperadas portrabalhadores no Brasil e na Argentina. 2013. 334 f. Tese (Doutorado em Planejamento Urbano e Regional) - Universidade Federal Rio de Janeiro, Rio de Janeiro, 2013.

HENRIQUES, F. C. et al. As empresas recuperadas por trabalhadores no Brasil: resultados de um levantamento nacional. Mercado de trabalho, n. 55, p. 55-67, ago. 2013.

. Empresas recuperadas por trabalhadores no Brasil. Rio de Janeiro: Editora Multifoco, 2013

HOLZMANN, L. Operários sem patrão: gestão cooperativa e dilemas da democracia. São Carlos: Editora da UFSCar, 2001.

JUVENAL, T. L. Empresas recuperadas por trabalhadores em regime de autogestão: reflexões à luz do caso brasileiro. Revista do BNDES, Rio de Janeiro, v. 13, n. 26, p. 115-138, dez. 2006.

KASMIR. S. The mith of Mondragón: cooperatives, politics and working-class life in a basque town. New York: University of New York, 1996.

KLEIMAN, F. Lições de catende: a construção de uma autogestão em Pernambuco. São Paulo: AnnaBlume; Recife: Fetape, 2008.

LAVILLE, J. L. Economia solidária, a perspectiva européia. Sociedade e estado, v. 16, n. 1-2, p. 57-99, 2001.

LEITE, M. de P. O trabalho no Brasil dos anos 2000: duas faces de um mesmo processo. In: ENCONTRO NACIONAL DA ABET, 11., 2009, Recife. Anais... Recife: ABET. 2009.

. et al. Os estudos sobre fábricas recuperadas: um estado da arte. In: LEITE, M. de P.; ARAUUJO, A. M. C.; LIMA, J. C. (Org.). O trabalho na economia solidária: entre a precariedade e a emancipação. São Paulo: Annablume, 2015. p. 205-235.

LIMA, J. C. As artimanhas da flexibilização: o trabalho terceirizado em cooperativas de produção. São Paulo: Terceira margem, 2002.

Reestruturação industrial, desemprego e autogestão: as cooperativas do Vale do Sinos. Sociologias, v. 10 , n. 19 , p. $212-249,2008$

LUXEMBURGO, R. Reforma o revolución. In: Obras escogidas. Bogotá: Editorial pluma, 1979. t. 1

MARTINS, L. H. Reflexões sobre um acontecimento social na área fabril: a experiência autogestionária da Markeli. 1998. Dissertação (Mestrado em Serviço Social) Universidade Estadual Paulista, Franca, 1998.

MARX, K. Manifesto do lançamento da Associação internacional dos trabalhadores, 1864. In: MARX, K.; ENGELS, F. Textos 3. São Paulo: Edições sociais, 1977.

NOVAES, H. T. O fetiche da tecnologia: a experiência das fábricas recuperadas. São Paulo: Expressão popular, $2007 a$.

De tsunami a marola: uma breve história das fábricas recuperadas na América Latina. Lutas $\mathcal{E}$ resistências, Londrina, n. 2, p. 84-97, 2007b. 1. sem.

PAULUCCI, M. A. O internacionalismo e as fábricas recuperadas. 2007. 106 f. Dissertacão (Mestrado em Sociologia Política) - Centro de Filosofia e Ciências Humanas, Universidade Federal de Santa Catarina, Florianópolis, 2007.

PEIXOTO, J. A. et al. Pesquisa exploratória nas empresas pioneiras. In: VALLE, R. (Org.). Autogestão: o que fazer quando as fábricas fecham? Rio de Janeiro: Relume dumará, 2002.

PIORE, M. J.; SABEL, C. F. The second industrial divide: possibilities for prosperity. New York: Basic books, 1984

PIRES, A. S. Autogestão, economia solidária e gênero: as trabalhadoras de cooperativas incubadas na cidade de São Carlos. 2010. 106 f. Dissertação (Mestrado em Sociologia) - Centro de Educação e Ciências Humanas, Universidade Federal de São Carlos, São Carlos, 2010.

O que aconteceu com as fábricas recuperadas? Uma retomada da questão da autogestão no Brasil. In: ENCONTRO ANUAL DA ANPOCS, 37., Águas de Lindoia. Anais... Águas de Lindoia: ANPOCS. 2013.

Fábricas recuperadas e os trabalhadores: a autogestão entre a teoria e a prática. 2014. $241 \mathrm{f}$. Tese (Doutorado em Sociologia) - Centro de Educação e Ciências Humanas, Universidade Federal de São Carlos, São Carlos, 2014

As fábricas recuperadas no Brasil: o desafio da autogestão. São Carlos: EdUFSCar, 2016.

RASLAN, F. O. Resistindo com classe: o caso da ocupação da Flaskô. 2007. 170 f. Dissertação (Mestrado em Sociologia) - Instituto de Filosofia e Ciências Humanas, Universidade Estadual de Campinas, Campinas, 2007.

REBÓN, J. La empresa de la autonomía: trabajadores recuperando la producción. Buenos Aires: Colectivo ediciones: Picaso, 2007.

; SAAVEDRA, I. Empresas recuperadas: la autogestión de los trabajadores. Buenos Aires: Capital intelectual, 2006.

RUFINO, S. (Re)fazer, (re)modelar, (re)criar: a autogestão no processo produtivo, 2005. $181 \mathrm{f}$. Tese (Doutorado) Universidade de São Paulo, São Paulo, 2005.

RUGGERI, A. (Org.). Las empresas recuperadas: autogestión obrera em Argentina y América Latina. Buenos Aires: Editorial de la Facultad de Filosofia y Letras, 2009.

et al. Las empresas recuperadas en la Argentina: informe del tercer relevamiento de empresas recuperadas por sus trabajadores. Buenos Aires: Ediciones de la Cooperativa Chilavert, 2011.

SANTOS, B. de S.; RODRÍGUEZ, C. Introdução: para ampliar o cânone da produção. In: SANTOS, B. de S. (Org.). Produzir para viver: os caminhos da producão não capitalista. Rio de Janeiro: Civilização brasileira, 2002.

SILVA, E. da. A atuação do movimento sindical frente ao processo de falência: os casos dos sindicatos dos mineiros/Criciúma e trabalhadores têxteis/Blumenau. 2005. 170 f. Dissertação (Mestrado em Desenvolvimento Regional) - Centro de Ciências Humanas da Comunicação, Universidade Regional de Blumenau, Blumenau, 2005.

SIMMEL, G. A determinação quantitativa dos grupos sociais. In: MORAES FILHO, E. de (Org.). Georg Simmel: 
sociologia. São Paulo: Ática, 1983.

SINGER, P. Introdução à Economia solidária. São Paulo: Editora Fundação Perseu Abramo, 2002.

TAYLOR, P. L. The rhetorical construction of efficiency: restructuring and industrial democracy in Mondragón, Spain. Sociological forum, v. 9, n. 3, p. 459-489, 1994.

THORNLEY, J. Worker's co-operatives and trade unions: the Italian experience. Economic and industrial democracy, v. 4, p. 321-344, 1983.

VALLE, R. O debate atual sobre o cooperativismo e autogestão no Brasil. In: VALLE, R. (Org.). Autogestão: o que fazer quando as fábricas fecham? Rio de Janeiro: Relume dumará, 2002. et al. Conclusões. In VALLE, R. (Org.). Autogestão: o que fazer quando as fábricas fecham? Rio de Janeiro: Relume dumará, 2002.

VIEITEZ, C. G.; DAL RI, N. M. Trabalho associado: cooperativas e empresas de autogestão. Rio de Janeiro: DPA, 2001.

WEBB, S.; WEBB, B. Co-operative production and profit sharing. Special supplement to the new statesman, v. 2, n. 45, 1914. 


\section{RECUPERATED FACTORIES BY WORKERS: the dilemmas of collective management of work}

\author{
Aline Suelen Pires \\ Jacob Carlos Lima
}

This article aims to analyze the dilemmas of the collective management in factories recuperated by workers in Brazil organized mostly in the 1990s. These factories were structured either as cooperatives or as hybrid forms of management, in a context of economic restructuring and of rising unemployment, in order to keep jobs. Generally, they had the support of labor unions, and progressively became part of the Solidarity Economy movement, which was institutionalized in the following decade. 20 years after the advent of the first projects of this kind, we sought not only to verify how they remained in the market and how they adapted to the political-economic changes of the period, but also to analyze their relation to the original proposals of self-management. This article has a longitudinal scope, seeking to study factories analyzed previously (in the late 1990s), which remained in activity. In addition, interviews with leaders and workers of the projects were made, as well as with leaders of support institutions such as ANTEAG and UNISOL Brazil. Although the ideals of cooperativism and self-management remain present in many workers' speech, its implementation has found many obstacles in practice since recuperated factories in order to become viable endure many market pressures, which eventually modify some of their initial objectives.

KeYwords: Work. Self-Management. Cooperativism. Solidarity Economy. Recuperated Factories.

\section{FABRIQUES RECUPEREES PAR LES \\ TRAVAILLEURS: les dilemmes de la gestion collective du travail}

\author{
Aline Suelen Pires \\ Jacob Carlos Lima
}

L'objectif de cet article est d'analyser les dilemmes de la gestion collective dans des fabriques récupérées par les travailleurs au Brésil et qui se sont organisées, dans leur plus grand nombre au cours des années 1990. Ces fabriques ont été structurées soit comme des coopératives soit sous des formes hybrides d'administration, dans un contexte de restructuration économique et d'augmentation du chômage, afin de pouvoir maintenir des postes de travail. En général elles ont eu le soutien de syndicats et se sont insérées progressivement dans le mouvement de l'Economie Solidaire qui s'est institutionalisée dans la décennie suivante. Vingt ans après l'appartition des premières entreprises de ce genre nous nous proposons non seulement de vérifier comment elles se maintiennent sur le marché et se sont adaptées aux changements politiques et économiques de cette période mais aussi d'analyser leur relation avec les propositions à l'origine de l'autogestion. La recherche s'est faite sur une coupure longitudinale pour essayer d'étudier les fabriques analysées antérieurement (à la fin des années 1990) et qui sont toujours en activité. Des interviews ont également été réalisées avec des leaders et des employés de ces entreprises ainsi qu'avec des responsables d'institutions de soutien telles que l'ANTEAG et l'UNISOL Brésil. Même si les idéaux du coopérativisme et de la dite autogestion sont toujours présents dans les discours de beaucoup de travailleurs, dans la pratique leur mise en place est confrontée à de nombreux obstacles vu que, pour rester viables, les fabriques récupérées affrontent les pressions du marché qui finissent par modifier quelques-uns de leurs objectifs initiaux.

Mots-clés: Travail. Autogestion. Coopérativisme. Economie solidaire. Fabriques récupérées.

\footnotetext{
Aline Suelen Pires - Doutora em Sociologia pela Universidade Federal de São Carlos (UFSCar), mestre em Sociologia e bacharel em Ciências Sociais pela mesma universidade. Atualmente, é professora adjunta do Departamento de Sociologia na UFSCar. É participante do Grupo de Estudos Trabalho e Mobilidades, na UFSCar, e do grupo Contradições do Trabalho no Brasil Atual: formalização, precariedade, terceirização e regulação, na Universidade de Campinas. Desenvolve pesquisas na área de Sociologia do Trabalho, principalmente nos temas: flexibilização do trabalho, cooperativismo e economia solidária, trabalho dos profissionais de Tecnologia da Informação.

Jacob Carlos Lima - É graduado em Ciências Políticas e Sociais pela Escola de Sociologia e Política de São Paulo (1979), mestre em Ciências Sociais (Sociologia) pela Pontifícia Universidade Católica de São Paulo (1983), doutor em Sociologia pela Universidade de São Paulo (1992), com Pós-doutorado no Department of Urban Studies and Development do Massachusetts Institute of Technology (EUA-2001). Atua em pesquisas nas áreas de Sociologia do Trabalho e Sociologia Econômica, destacando-se nas seguintes temáticas: reestruturação produtiva, reespacialização da produção; trabalho flexível; trabalho informal; empreendedorismo; redes sociais e mercados de trabalho urbanos; trabalho informacional; cooperativas de trabalho e economia solidária; culturas do trabalho e mobilidades.
} 
